\title{
AS ESTRUTURAS DE GESTÃO E PLANEJAMENTO DA ARBORIZAÇÃO URBANA DE PONTA GROSSA - PR
}

\author{
Danielle Cristina Carneiro
}

\section{Silvia Méri Carvalho}

RESUMO: Este trabalho tem como objetivo compreender as estruturas disponibilizadas pelo poder público e privado no que tange a arborização viária, por meio da análise das ações implantadas atualmente pela Prefeitura Municipal de Ponta Grossa e COPEL - Companhia Paranaense de Energia. Para tanto se utilizou como metodologia a aplicação de entrevistas aos funcionários de ambos os órgãos, além do levantamento bibliográfico sob o aspecto jurídico relacionado à arborização urbana. Conclui-se que os dois órgãos apresentam significativas diferenciações quanto à estrutura e ao planejamento, o que reflete na condição atual do gerenciamento das árvores urbanas.

Palavras chave: Arborização urbana. Prefeitura Municipal de Ponta Grossa. COPEL.

\section{INTRODUÇÃO}

A transformação da paisagem em ambiente urbano ao longo dos tempos transformou não apenas o espaço, visível, tangível e complexo, mas também o autor 


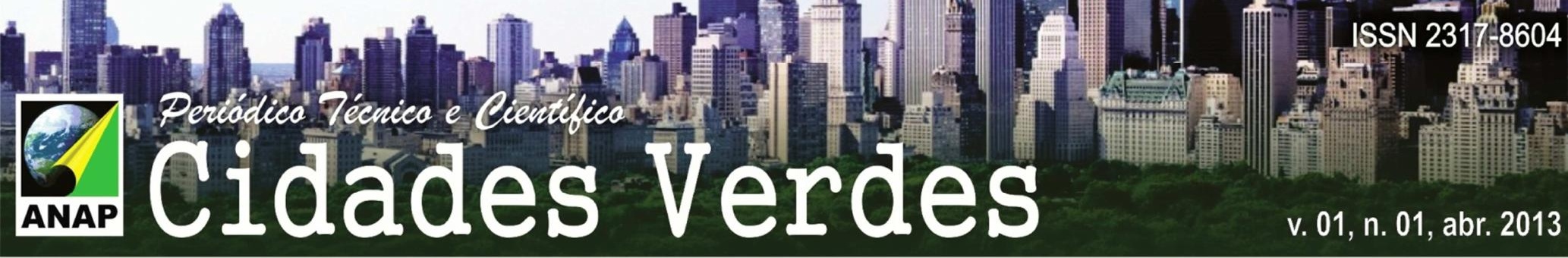

dessas modificações, o ser humano, seu modo de viver, suas necessidades e suas relações sociais.

A crescente e nítida magnitude dos problemas urbanos no Brasil, seja nos aspectos ambientais, sociais e econômicos, aliada à precariedade do planejamento por parte do poder público faz com que a qualidade de vida, condição mínima de vivência por parte da população, seja um objetivo a ser conquistado por todos. Partindo desta premissa, torna-se fundamental por parte dos órgãos públicos que o planejamento urbano seja plenamente desenvolvido, levando-se em consideração a sustentabilidade do espaço, como garantia a uma vivência digna.

O fato já constatado para a população brasileira que se encontra em sua maioria (mais de $80 \%$ ) em áreas urbanas se repete igualmente na cidade de Ponta Grossa: dos 94.849 domicílios particulares que abrigam 311.611 habitantes, 97,84\% estão na zona urbana (IBGE, 2010).

A partir disso verifica-se que a população pontagrossense encontra-se quase em sua maioria no centro urbano e repensar a qualidade de vida que estas pessoas devem alcançar nesse espaço torna-se fundamental, a partir da premissa básica da gestão urbana.

Para Louro e Menezes (2012) a gestão urbana deve ser entendida como a gestão da cidade, relacionada com o conjunto de recursos e instrumentos da administração aplicados na cidade, visando à qualidade da infraestrutura e dos serviços urbanos, propiciando melhores condições de vida e aproximando os moradores nas decisões e ações da gestão municipal. Ainda neste sentido, a gestão ambiental urbana é o gerenciamento do espaço de forma sustentável, por meio da articulação das ações dos diferentes agentes sociais que interagem no espaço urbano (LOURO E MENEZES, 2012).

No caso da cidade de Ponta Grossa, Paraná, a gestão urbana voltada às questões ambientais não foi um dos aspectos centrais que nortearam o processo de desenvolvimento e expansão da cidade (QUADROS, 2009).

É neste sentido que a arborização urbana se insere como um dos principais ícones em defesa ao meio ambiente urbano. A arborização é entendida como toda cobertura vegetal de porte arbóreo existente nas cidades, e atua em vários níveis na qualidade de 
vida, produzindo inúmeros benefícios, como adsorção de gases tóxicos, melhoria da qualidade do ar, redução de níveis de ruído, equilíbrio ambiental e redução da temperatura do ar (SANTOS e TEIXEIRA, 2001).

Sendo assim, no âmbito da cidade de Ponta Grossa, observa-se que estes fatores, necessários e fundamentais à qualidade de vida, muitas vezes não são tão valorizados quanto deveriam ser: na atual gestão pública da cidade percebe-se que estes benefícios por parte da arborização muitas vezes acabam minimizados pela falta de mão de obra especializada, pelo costume de podas não realizadas corretamente, além do próprio descaso e desconhecimento que muitos tratam o assunto (QUADROS, 2009).

Este trabalho objetiva o maior esclarecimento quanto às estruturas municipais voltadas à arborização: por um lado a gerência pública, que por meio da Prefeitura Municipal de Ponta Grossa administra as árvores urbanas, desde sua implantação à manutenção; e por outro viés a COPEL - Companhia Paranaense de Energia, que por meio de uma visão diferenciada participa da manutenção das árvores encontradas abaixo de suas estruturas de energia.

\section{A ARBORIZAÇÃO URBANA VIÁRIA NO CONTEXTO DA GESTÃO}

O fato de que a maioria das cidades brasileiras passa por um processo acelerado e contínuo de urbanização não é mais novidade. De um modo geral, os grandes centros encontram neste momento um desafio urgente de planejar o futuro, onde as questões socioambientais se acentuam.

Neste sentido a cidade, como organismo dinâmico e complexo, pode ser caracterizada por múltiplos contrastes e características, o que muitas vezes gera dificuldade ao gestor público. Rezende e Frey (2005) comentam que "a gestão urbana deve desempenhar um papel relevante para contribuir na diminuição desses contrastes, dificuldades e conflitos e também na solução dos múltiplos problemas enfrentados" (REZENDE e FREY, 2005, p. 53). 
Dificuldades e conflitos estes, contextualizados em nível nacional brasileiro, podem ser caracterizados geralmente como problemas de habitação, infraestrutura e serviços, que recaem como prioridades ao poder local, que na maioria das vezes não atende à demanda no tempo necessário. Para Pizzol (2006), seria, portanto, impossível discutir a sustentabilidade urbana sem minimizar os níveis de pobreza, universalizar os serviços de infraestrutura, saúde e educação, reduzir o uso ilegal do solo e a violência urbana, bem como, combater a poluição e degradação ambiental e conservar o patrimônio histórico e ambiental.

Restringindo-se, portanto, ao âmbito da gestão ambiental, a arborização urbana insere-se neste contexto como um dos principais fatores em defesa ao meio ambiente urbano.

Neste sentido, Moro (1976, p. 15 apud LOBODA; ANGELIS, 2005, p. 130) discorre:

[...] a constante urbanização nos permite assistir, em nossos grandes centros urbanos, a problemas cruciais do desenvolvimento nada harmonioso entre a cidade e a natureza. Assim, podemos observar a substituição de valores naturais por ruídos, concreto, máquinas, edificações, poluição etc..., e que ocasiona entre a obra do homem e a natureza crises ambientais cujos reflexos negativos contribuem para degeneração do meio ambiente urbano, proporcionando condições nada ideais para a sobrevivência humana.

Sendo assim, percebe-se que a degradação do ambiente natural nas cidades e os poucos espaços que às árvores é destinado, faz com que a questão da arborização em cidades seja essencial, no sentido de garantir à população o bem-estar e qualidade de vida, características estas intrinsecamente ligadas às áreas verdes públicas.

Para que seja esclarecida a acepção da palavra "arborização" utiliza-se para este trabalho o significado dado por Santos e Teixeira (2001, p. 55):

A simples presença de árvores ao longo de vias não qualifica as arborizações. São comuns altas populações que incluem árvores quebradas, disformes, doentes e até mortas. Considera-se arborização o conjunto de exemplares arbóreos de porte e forma compatível com o espaço, sem problemas físicos ou sanitários.

Além da arborização, consideram-se ainda definições de expressões utilizadas no contexto, como os termos apontados em Lima et al. (1994): 
1. Espaço livre: Trata-se do conceito mais abrangente, integrando os demais e contrapondo-se ao espaço construído em áreas urbanas.

2.Área verde: Onde há o predomínio de vegetação arbórea, englobando as praças, os jardins públicos e os parques urbanos. Os canteiros centrais de avenidas e os trevos e rotatórias de vias públicas que exercem apenas funções estéticas e ecológicas, devem, também, conceituar-se como área verde. Entretanto, as árvores que acompanham o leito das vias públicas não devem ser consideradas como tal, pois as calçadas são impermeabilizadas.

3. Parque urbano: É uma área verde, com função ecológica, estética e de lazer, no entanto com uma extensão maior que as praças e jardins públicos.

4. Praça: É um espaço livre público cuja principal função é o lazer. Pode não ser uma área verde, quando não tem vegetação e encontra-se impermeabilizada. 5. Arborização urbana: Diz respeito aos elementos vegetais de porte arbóreo dentro da cidade. Nesse enfoque, as árvores plantadas em calçadas fazem parte da arborização urbana, porém não integram o sistema de áreas verdes.

Sendo assim, Bonametti (2003) ainda comenta que a arborização urbana pode ser explicada através da sociedade que as produz. Pode-se, portanto, abarcá-la enquanto um produto da história das relações materiais dos homens que, a cada momento, adquire uma nova dimensão, o qual aparece através da relação entre o construído (como casas, ruas e avenidas) e o não construído (o natural) de um lado e, do outro, o movimento, no que se refere ao deslocamento de homens e mercadorias, produzindo assim uma interação entre as vias de circulação e a vegetação da cidade.

Neste sentido, e utilizando-se dos conceitos e ideias previamente explanadas, é de grande relevância a discussão a respeito da arborização urbana, especificadamente no contexto brasileiro. Ainda de acordo com Bonametti (2003, p. 54) "As cidades brasileiras possuem na sua maioria áreas urbanas arborizadas, mas estas são pouco organizadas e com quase nenhuma preocupação quanto à escolha adequada das espécies vegetais, principalmente nas vias urbanas". Desta maneira, e em consonância com a citação, Santos e Teixeira (2001, p. 17) ainda comentam:

[...] a árvore como elemento estruturador de espaços, responsável por qualidades estético-visuais e de bem-estar, passa a constituir um problema urbano, decorrente de planos ineficientes, inexistência de políticas no setor, improvisos e falta de conscientização. A falta de técnicos específicos na área aliado à falta de informações e pesquisa tem gerado o insucesso de alguns empreendimentos e receio de novas investidas. 
Sendo assim, este trabalho objetiva compreender as estruturas disponibilizadas pelo poder público e privado no que tange a arborização viária, por meio da análise das ações implantadas atualmente pela Prefeitura Municipal de Ponta Grossa e COPEL Companhia Paranaense de Energia, especificamente na cidade de Ponta Grossa - Pr.

\section{MATERIAIS E MÉTODOS}

Localizada a 103 quilômetros da capital Curitiba, a cidade de Ponta Grossa possui apenas $57,2 \%$ de seu espaço urbano arborizado, de acordo com o IBGE (2010), índice este baixo comparado a outras cidades do Estado, como Maringá, que possui 97,5\% e Londrina, com 96,5\%. Para a compreensão de como a arborização é tratada na cidade, foram levantadas e analisadas as ações públicas e privadas que incidem sobre as árvores urbanas, levando em consideração a Prefeitura Municipal de Ponta Grossa, especificamente através de sua Secretaria de Agricultura, Pecuária e Meio Ambiente (SAPMA), juntamente com a secretaria de Obras e Serviços Públicos; e a COPEL Companhia Paranaense de Energia, que através de políticas específicas promove a manutenção da arborização da cidade.

Para aprofundar os conhecimentos a respeito das políticas públicas envolvidas no âmbito do planejamento urbano voltado às árvores viárias, foram realizadas entrevistas com técnicos vinculados aos dois órgãos: Prefeitura e Copel. As entrevistas foram concedidas nos meses de setembro e outubro de 2012, as quais constavam de perguntas abertas a fim de melhor entender o processo de arborização na cidade, além dos custos às instituições e principais problemas, conforme o Anexo 1.

Buscou-se além do embasamento teórico voltado à literatura existente em relação à arborização urbana, um respaldo jurídico, por meio de leis e decretos, o qual propiciou um maior apoio legal e conhecimento no aspecto relacionado às árvores urbanas. 


\section{PlANEJAMENTO E GERENCIAMENTO DA ARBORIZAÇÃO URBANA NAS ESFERAS PÚBLICA E PRIVADA}

Considerando todos os benefícios, e contextualizando a realidade em âmbito municipal vivenciada atualmente, percebe-se que infelizmente a situação das árvores de acompanhamento viário da cidade de Ponta Grossa, Paraná, não é valorizada, uma vez que a cidade de Ponta Grossa possui pouco mais da metade de seu espaço urbano arborizado.

Sendo assim, a questão da arborização municipal, ou a falta dela, no caso, pode ainda ser historicamente esclarecida: com ruas estreitas e atividades ligadas ao gado e à madeira; a cidade voltou suas ações a equipamentos urbanos, não pensando na arborização de vias públicas. Neste sentido, afirma Quadros (2009, p. 127):

Pode-se constatar a existência de uma diversidade de problemas relacionados à distribuição da arborização urbana na cidade [de Ponta Grossa]. Destaca-se a consciência de que como um qualificador urbano, as árvores oferecem inúmeros benefícios, e simultaneamente que o crescimento desordenado da cidade acarretou inúmeros problemas relacionados à sua infra-estrutura.

Em concordância com a citação, pode-se ainda afirmar que a falta de um Plano de Arborização Municipal demonstra ainda mais o reflexo da falta do planejamento da mesma no que tange a arborização. Neste sentido, um Plano de Arborização deve ser um instrumento de caráter técnico, norteador das decisões sobre quaisquer aspectos relacionados à arborização, aplicado às condições e características de cada município (PARANÁ, 2012).

Percebe-se que mesmo contando com o Plano Diretor Municipal e diversas leis, destacadas mais adiante neste texto, a cidade de Ponta Grossa - Pr, ainda não conta com um efetivo sistema de planejamento para o plantio e manejo de árvores, tanto em sua porção central quanto nos bairros (QUADROS, 2005; SILVA, 2006 ,VILELA, 2007, MIRANDA, 2008, LUZ, 2009, MEISTER, 2009).

O gerenciamento da produção de mudas, plantio e manutenção das árvores urbanas é coordenado e efetivado pela Prefeitura Municipal de Ponta Grossa, através das 
secretarias de Agricultura, Pecuária e Meio Ambiente e Secretaria de Obras. O gerenciamento da COPEL - Companhia Paranaense de Energia, que atua na manutenção das árvores, especificamente por meio das ações de poda em árvores que se encontram abaixo da estrutura de energia elétrica, é realizado por uma divisão de acompanhamento de manutenção.

Estas ações, no entanto, precisam ser melhor compreendidas partindo-se do contexto da gestão urbana de Ponta Grossa, por meio de uma análise específica da arborização da cidade, buscando-se um maior aprofundamento desse tema e uma maior compreensão das estruturas disponibilizadas para as ações da arborização a partir de entrevistas com funcionários de ambos os órgãos, do respaldo jurídico e da bibliografia voltada ao assunto.

\subsection{ASPECTOS DA ARBORIZAÇÃO ABRANGIDOS PELA PREFEITURA MUNICIPAL DE PONTA GROSSA}

De acordo com Leal (2009), as árvores de rua têm características particulares que diferem daquelas utilizadas em áreas verdes públicas ou particulares. Neste sentido, em consonância com Milano (1994), planejar a arborização de ruas é, de forma resumida, escolher a árvore certa no local certo, sem confundir os objetivos do planejador e a função da árvore no ambiente urbano. Biondi e Neto (2011) ainda afirmam que no planejamento da arborização viária é imprescindível o conhecimento da estrutura urbana, para não haver conflitos entre árvore e ambiente.

Ainda para Milano (1994), as atividades relacionadas à arborização urbana podem ser divididas em quatro passos:

a) Planejamento e controle - É a definição detalhada de planos, programas e projetos e o controle da realização dos mesmos quanto aos objetivos estabelecidos e resultados obtidos;

b) Implantação - É a efetivação prática das propostas estabelecidas no planejamento, incluindo a produção de mudas e seu efetivo plantio, com todos os seus diversificados e detalhados procedimentos; 


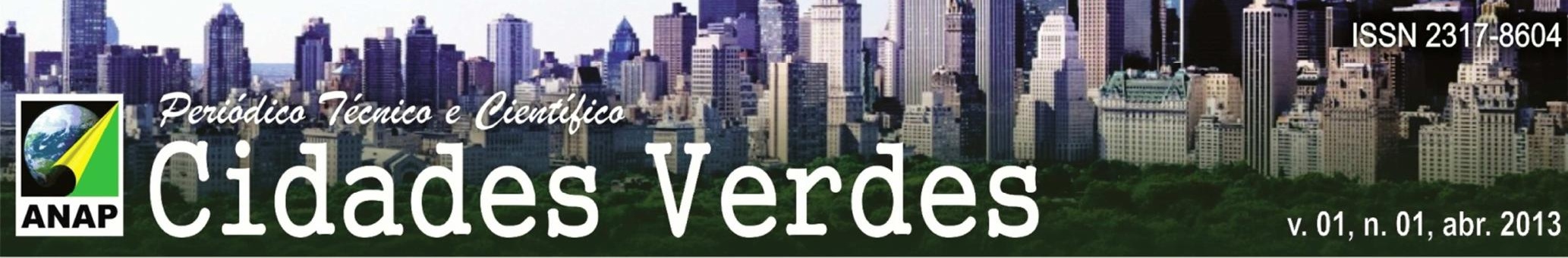

de 2008, comenta que as ruas e avenidas devem ter arborização nas duas faces e uma árvore para cada lote ou no mínimo a cada doze metros.

Nesse mesmo sentido, o Decreto ํo 305/2003, de 13 de junho de 2003, em seu 3ํㅜㅇ artigo dispõe que é vedado o corte, derrubada ou a prática de qualquer ação que possa provocar dano, alteração do desenvolvimento natural ou morte de elemento arbóreo em bem público ou em terreno particular, e em parágrafo único comenta que o corte de elementos arbóreos somente será permitido após a realização da vistoria e expedição de autorização pela Prefeitura Municipal de Ponta Grossa, através de sua Secretaria de Agricultura, Pecuária e Meio Ambiente.

Considerando ainda o Decreto n 1573, de 19 de julho de 2007, o qual institui e regulamenta a adoção de jardins em canteiros, praças e parques por entidades públicas ou privadas, percebe-se que o próprio decreto admite que "é grande o número e avantajada a extensão de canteiros, praças e parques, absorvendo para a sua conservação e manutenção mão-de-obra em montante superior aos recursos humanos da municipalidade" (PMPG, 2012). Por conseguinte, dispõe em seu artigo 2o que "a atividade de implantação, conservação e manutenção de jardins em canteiros centrais e laterais de vias, praças e parques poderão ser prestadas por pessoas físicas, por empresas ou entidades da sociedade civil organizada do município de Ponta Grossa, através de permissão outorgada pelo poder público, em caráter precário, gratuitamente, por prazo de um ano, renovável".

É, portanto, a partir de leis e decretos existentes para a cidade de Ponta Grossa que a Prefeitura Municipal deveria exercer sua função de coordenar e garantir que a arborização urbana seja realizada e normatizada. Uma vez que nem todas as leis são plenamente cumpridas, muitas sendo esquecidas ou ignoradas, percebe-se que para melhor compreender desta questão é necessário analisar a estrutura que o poder público oferece em relação às árvores urbanas viárias, desde sua implantação e manejo, além de conhecer como o planejamento em relação às árvores é efetivado e realizado atualmente.

A Prefeitura Municipal de Ponta Grossa encontra-se subdividida em 13 secretarias, número este que varia de acordo com o gestor público e no caso específico do Meio Ambiente, nas duas últimas gestões esteve incorporada a outras duas pastas (Agricultura 
e Pecuária), ou seja, não possuía secretaria própria. Em relação à arborização, as secretarias de "Agricultura, Pecuária e Meio Ambiente" (SAPMA), juntamente com a secretaria de "Obras e Serviços Públicos" são as responsáveis por todo o processo de cuidados, implantação, poda, manejo e fiscalização das árvores (Figura 1). Neste sentido, a Prefeitura Municipal ainda conta com o Viveiro Municipal, local este onde as mudas são cultivadas até o porte ideal para a implantação.

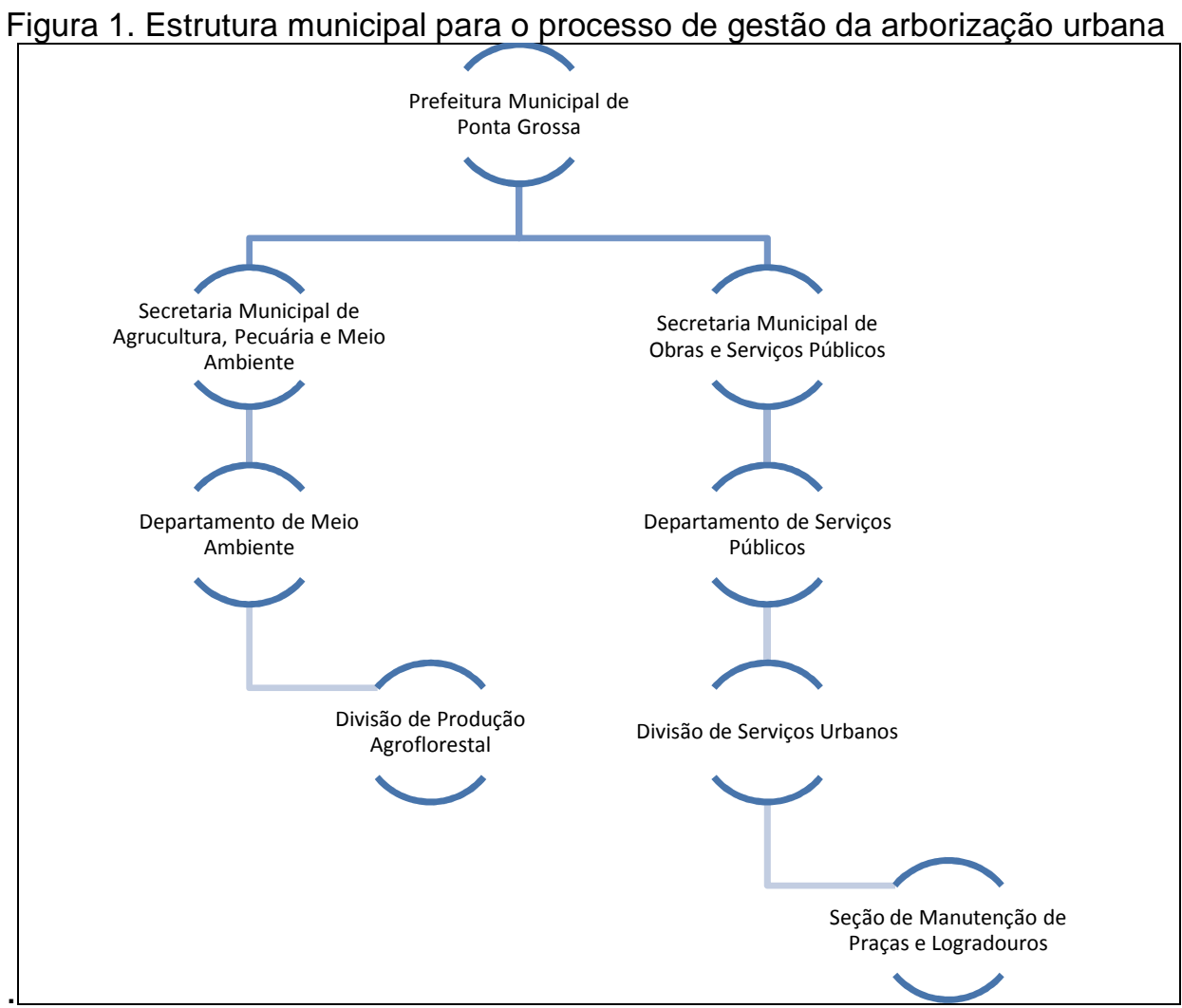

Org: CARNEIRO, 2012

Na secretaria de Agricultura, Pecuária e Meio Ambiente, a qual é subdividida em departamentos, encontra-se o departamento de Meio Ambiente, o qual por meio da divisão de Produção Agroflorestal é responsável pela arborização municipal.

De acordo com a chefe da Divisão de Produção Agroflorestal, esse órgão é responsável pelas árvores viárias urbanas. Contando com um total de 18 funcionários, a secretaria é responsável pelo planejamento, implantação, manutenção e fiscalização dos elementos arbóreos da cidade de Ponta Grossa. 


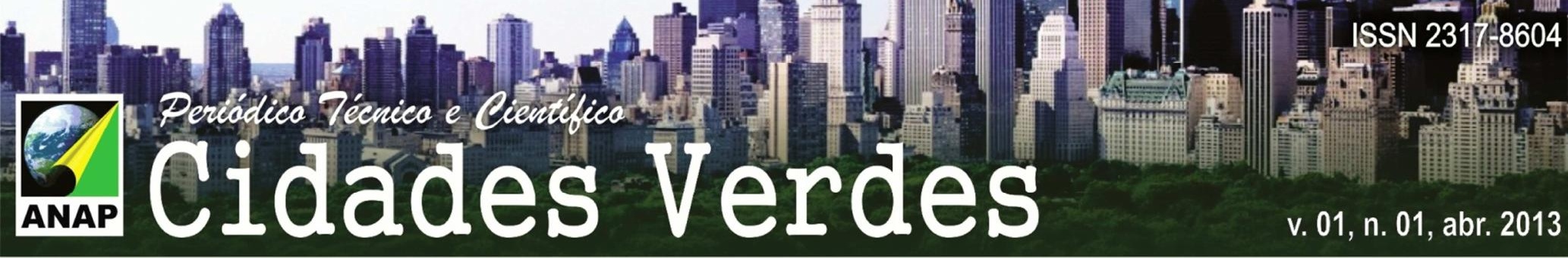

A secretaria, no entanto, não possui o total de árvores viárias às quais é responsável, contando apenas com os dados obtidos pela Universidade Estadual de Ponta Grossa, que, em trabalhos acadêmicos, elencou um total de 8.771 árvores em seis bairros da cidade (QUADROS, 2005; SILVA, 2006, VILELA, 2007, MIRANDA, 2008, LUZ, 2009, MEISTER, 2009). Para Leal (2011), a inexistência de um banco de dados das árvores em vias públicas por parte dos órgãos municipais é um dos principais entraves para a elaboração de pesquisas acadêmicas relacionadas ao assunto.

Em se tratando da implantação das árvores, o Viveiro Municipal é o local que tem por função produzir mudas para a implantação de árvores na cidade, e mantêm em média 14.000 mudas ao ano, prontas para o plantio, que é realizado apenas após a aprovação da Secretaria de Agricultura, Pecuária e Meio Ambiente. De acordo com a chefe da seção, as árvores são disponibilizadas para plantio em média com 1,80 metros de altura, sendo então plantadas em loteamentos governamentais, novas vias ou entregues aos munícipes, que previamente devem ter requisitado a muda à SAPMA.

O Viveiro Municipal conta ainda com mais três funcionários, os quais têm o trabalho de adubar, podar, irrigar e cuidar das mudas. Em sua maioria, as mudas são provenientes das próprias sementes de árvores nativas da cidade. Algumas, no entanto, são resultados de multas aplicadas, baseadas no Código de Postura do Município de Ponta Grossa, o qual na seção III, artigo 16, sanciona a proibição do corte de qualquer árvore, que, muitas vezes não são pagas em espécie, conforme o Código de Postura, mas sim convertidas em árvores, com o consentimento do secretario da SAPMA.

As penalidades são advertência, seguida de multa. $\mathrm{O}$ artigo 92 mostra que a multa vai de 20 a 70 VR (valor de referência). Em outubro de 2012 o valor de uma VR era de $R \$$ 34,81, ou seja, a multa iria de $R \$ 696,10$ a $R \$ 2.436,70$, dependendo do agravante cometido, o qual normalmente é julgado pelo Engenheiro Agrônomo da Prefeitura.

Muitas vezes, quando o infrator alega o desconhecimento da lei, e o secretário da SAPMA aceita, a multa é apenas revertida em mudas, que devem ser entregues ao Viveiro Municipal, escolhidas pela Secretaria. Ainda de acordo com o engenheiro agrônomo, em média há 100 multas por corte ilegal ao ano. As denuncias são realizadas 


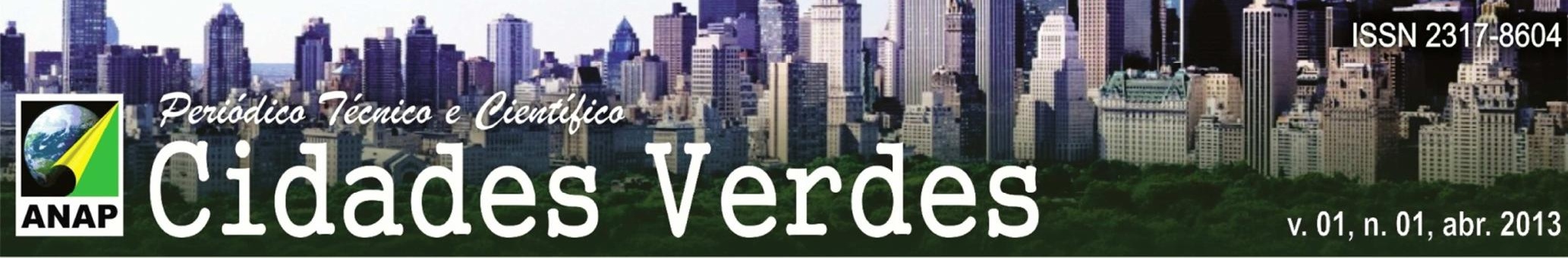

pelos próprios cidadãos da cidade, ou pelos funcionários da SAPMA, que têm o papel também de fiscalizar a arborização.

O monitoramento da arborização ainda é escasso, uma vez que o número de funcionários existentes é muito inferior proporcionalmente ao de árvores viárias, e muitas infrações passam despercebidas. De acordo com a chefe da divisão de produção agroflorestal, desde o começo do ano de 2012, até o mês de setembro, houve 227 processos de corte e poda na cidade, número este baixo em vista da quantidade de árvores totais na cidade.

O trabalho específico de poda e corte de árvores é realizado pela Secretaria Municipal de Obras e Serviços Públicos, que por meio da divisão de Serviços Urbanos e a subdivisão de Manutenção de Praças e Logradouros desenvolve as atividades de manejo das árvores urbanas que não se encontram abaixo da estrutura de rede elétrica.

De acordo com o diretor do departamento de Serviços Públicos, a secretaria conta com o número de oito funcionários para a poda e corte de árvores, quando o ideal seriam no mínimo 20 pessoas. Em média são 500 árvores podadas ao ano, número baixo se considerada a quantidade de árvores na cidade. As podas são realizadas, em geral, anualmente após a última geada, sem um cronograma fixo ou planejamento exato, ou quando um morador requer à SAPMA a poda.

Um dos grandes problemas em relação às podas e cortes de árvore são os resíduos decorrentes de tais ações, como galhos e folhas. De acordo com o diretor do departamento de Serviços Públicos, estes resíduos não têm destino certo, sendo na maioria das vezes descartados a céu aberto, mais especificamente em frente ao Matadouro Municipal de Ponta Grossa, localizado na porção leste (bairro de Uvaranas), área esta afastada da área central da cidade.

De acordo com Baratta Junior (2007), a disposição final dos resíduos sólidos produzidos no meio urbano, especificamente dos resíduos provenientes de podas e cortes de árvores, é um problema ambiental grave, uma vez que o ideal seria a estabilização destes resíduos através de processos biológicos controlados, permitindo a reciclagem dos nutrientes e a utilização da matéria orgânica. Uma vez que estes resíduos geram um 
grande volume de material vegetal que poderiam ser aproveitados, 0 ideal seria transformá-los em carvão, lenha ou compostagem.

A partir da observação da estrutura que a Prefeitura Municipal de Ponta Grossa disponibiliza para a arborização urbana, percebe-se que um dos entraves para as ações ligadas a ela é a própria divisão dos serviços em duas secretarias, opinião esta compartilhada pela chefe da Divisão de Produção Agroflorestal. Outra questão é a própria política atual, que não elenca a arborização urbana como uma das prioridades na cidade, e não oferece às secretarias recursos humanos e financeiros necessários para que a atividade seja executada plenamente.

A arborização da cidade, entretanto, não acontece apenas via Prefeitura Municipal. Para as árvores que se encontram abaixo da estrutura da rede elétrica, a poda e manejo são realizados pela COPEL - Companhia Paranaense de Energia, a qual conta com uma estrutura diferenciada para as ações relacionadas às árvores urbanas.

\subsection{ASPECTOS DA ARBORIZAÇÃO URBANA ABRANGIDOS PELA COPEL - COMPANHIA PARANAENSE DE ENERGIA.}

A competição por espaço entre árvores e redes aéreas de distribuição de eletricidade e de comunicação é um fato comum nos centros urbanos. É neste sentido que a COPEL atua na arborização viária, nos municípios do Estado do Paraná, com o intuito de promover a convivência harmônica entre as redes de distribuição de energia elétrica e as árvores existentes sob ela.

Como parâmetros para a correta administração e planejamento destas árvores, a Companhia se utiliza do Guia de Arborização de Vias Públicas e do convênio com os municípios do Estado, os quais estão contidos no Programa de Responsabilidade Socioambiental de Arborização Urbana da COPEL.

O Guia de Arborização de Vias Públicas é uma fonte de informações técnicas e práticas sobre espécies de árvores e redes de energia, o qual conta com sua versão 


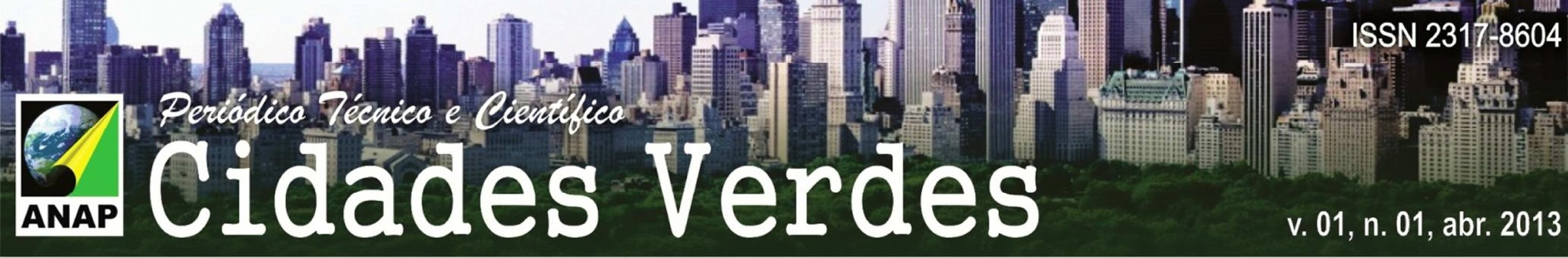

eletrônica, orientando o processo de escolha de espécies de maneira a evitar, no futuro, conflitos com as redes de distribuição de eletricidade. (COPEL, 2012)

Os convênios com as cidades visam o planejamento da arborização urbana e a minimização dos conflitos das árvores com as redes aéreas, além da substituição de árvores inadequadas sob redes de energia e o fornecimento de mudas, as quais, em hortos próprios nas usinas de Segredo, Salto Caxias e Mourão (Paraná), podem ser disponibilizados às cidades conveniadas. Infelizmente a cidade de Ponta Grossa não é uma das cidades conveniadas a este programa da COPEL.

Dentre as diversas ações desenvolvidas estão publicações técnicas, produção e fornecimento de mudas, substituição de árvores de risco e aprimoramento de técnicas de podas. Sendo ainda afiliada à Sociedade Brasileira de Arborização Urbana - SBAU e à International Society of Arboriculture - ISA, a Companhia participa ativamente de atividades relacionadas à arborização. (COPEL, 2012)

Ainda de acordo com a COPEL a arborização urbana sem manutenção e planejamento adequados, os quais são de competência das Prefeituras Municipais, tem provocado interferências nos sistemas de distribuição de energia elétrica. As causas são o rompimento de cabos, queima de eletrodomésticos, prejuízos à iluminação pública, curto-circuito, interrupções no fornecimento e risco de morte aos transeuntes. Deve-se ainda levar em consideração que o toque dos galhos nos condutores ou mesmo a queda de árvores sobre as redes elétricas estão entre as principais causas de desligamentos não programados das redes de distribuição de energia elétrica, ao lado dos temporais com raios e vendavais.

Especificamente na cidade de Ponta Grossa, a COPEL tem suas atividades mais relevantes no aspecto das podas de árvores viárias. Em entrevista concedida pelo gerente de manutenção da Unidade de Ponta Grossa, a COPEL trabalha, em média, com 4.500 árvores, as quais se encontram localizadas abaixo das estruturas de rede elétrica.

Contando com um total de 16 funcionários voltados à arborização, dentre eletricistas e técnicos (todos especializados por meio de cursos voltados à arborização), além de empresas terceirizadas (empreiteiras), a COPEL possui um cronograma anual para a realização de podas de árvores urbanas em Ponta Grossa. De janeiro a outubro de 
A partir da análise realizada na Prefeitura Municipal de Ponta Grossa e na COPEL por meio de entrevistas, observa-se que em relação à arborização urbana, ambos os órgãos apresentam diferenciações quanto à estrutura e ao planejamento voltados às árvores urbanas, conforme a Figura 2.

Figura 2. Diferenças e similaridades na gestão e planejamento da arborização urbana entre Prefeitura Municipal e COPEL

\begin{tabular}{|c|c|c|}
\hline & $\begin{array}{l}{ }^{\star} \text { Prefeitura Municipal de } \\
\text { Ponta Grossa }\end{array}$ & COPEL \\
\hline $\begin{array}{c}\text { Número de funcionários } \\
\text { totais }\end{array}$ & $\begin{array}{c}31 \text { funcionários } \\
\text { (18 na SAPMA, } 4 \text { no Viveiro } \\
\text { Municipal e } 9 \text { na Secretaria } \\
\text { de Obras. }\end{array}$ & $\begin{array}{c}19 \text { funcionários } \\
\text { especializados } \\
\text { (3 de empreiteiras } \\
\text { terceirizadas) }\end{array}$ \\
\hline $\begin{array}{l}\text { Número de funcionários } \\
\text { para o serviço de podas }\end{array}$ & 8 funcionários & 3 funcionários terceirizados \\
\hline $\begin{array}{c}\text { Número de árvores } \\
\text { atendidas }\end{array}$ & $\begin{array}{c}\text { Não há o conhecimento da } \\
\text { quantidade** }\end{array}$ & 4.500 \\
\hline $\begin{array}{l}\text { Quantidades médias de } \\
\text { podas realizadas no ano }\end{array}$ & Em média 500 por ano & $\begin{array}{c}8.324 \\
\text { (jan a out de 2012) }\end{array}$ \\
\hline $\begin{array}{c}\text { Valores de poda (para uma } \\
\text { árvore) }\end{array}$ & 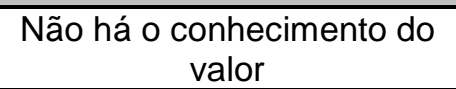 & $\mathrm{R} \$ 40,00$ \\
\hline Frequência entre as podas & Anualmente & $\begin{array}{c}\text { A cada seis meses, e em } \\
\text { alguns casos a cada três } \\
\text { meses. }\end{array}$ \\
\hline $\begin{array}{c}\text { Destino final de resíduos } \\
\text { das podas }\end{array}$ & $\begin{array}{l}\text { Despejados em frente ao } \\
\text { Matadouro Municipal de } \\
\text { Ponta Grossa }\end{array}$ & $\begin{array}{l}\text { Despejados em frente ao } \\
\text { Matadouro Municipal de } \\
\text { Ponta Grossa }\end{array}$ \\
\hline
\end{tabular}

*(representada pela Secretaria de Agricultura, Pecuária e Meio Ambiente e Secretaria de Obras)

** Contam apenas com os dados obtidos pela Universidade Estadual de Ponta Grossa, que em trabalhos acadêmicos elencou um total de 8.771 árvores em seis bairros da cidade.

Org: CARNEIRO, 2012

Percebe-se, portanto, que as estruturas relacionadas à arborização urbana realizadas pela Prefeitura Municipal e COPEL diferem-se em muitos aspectos. A Companhia atua somente sobre as árvores localizadas abaixo da estrutura de rede elétrica, e a Prefeitura, por sua vez, atua sobre todos os indivíduos arbóreos, inclusive aqueles localizados em praças, contando, portanto, com um maior número de árvores. Mesmo que o número exato não seja conhecido, percebe-se que um número maior de 
funcionários voltados a estas questões é exigido. Um ponto, no entanto, é atípico: o fato de que o número de podas realizadas pela Prefeitura é significativamente menor quando comparado à COPEL, mesmo contando com mais funcionários para esta função.

Percebe-se ainda que os dados da COPEL são facilmente localizados, com valores e informações exatas, enquanto os da Prefeitura são menos específicos, denotando assim uma maior organização e conhecimento das ações de arborização por parte da Companhia.

\section{CONSIDERAÇÕES FINAIS}

Mesmo sendo de competência da Prefeitura Municipal regulamentar, gerenciar e fazer a manutenção das árvores percebe-se que na maioria das vezes estas atividades não são planejadas. Apesar de contar com leis e decretos que normatizam as questões da arborização, o número de funcionários ainda é relativamente pequeno comparado à quantidade das árvores de rua. Outra questão é o fato da divisão em duas secretarias de Agricultura, Pecuária e Meio Ambiente, e a secretaria de Obras e Serviços Públicos, ambas com trabalhos voltadas à arborização, mas que por se localizarem em espaços diferentes, e mesmo tendo funções diferenciadas, a realização dos trabalhos é dificultada pela falta de comunicação.

Outra questão pertinente é o fato de que algumas vezes as multas relacionadas à poda e ao corte indevido de árvores são pagas em mudas, ao invés dos valores monetários, fato este que promove o descaso por parte do cidadão, que pelo fato minimizado e facilmente convertido em mudas, não sente a real consequência de suas ações.

Em relação à COPEL, que no município de Ponta Grossa trabalha mais ativamente no sentido de podas, percebe-se que o planejamento é mais detalhado, as podas mais constantes, e os valores gastos na realização dos trabalhos são facilmente encontrados. 
Em função do trabalho ser também realizado por empresas terceirizadas, as ações de gerenciamento e planejamento são mais coordenadas.

Um problema ambiental concomitante às duas instâncias é o fato do destino final de resíduos das podas: ambos não têm local adequado para isso, tornando-se um problema ambiental para o município de Ponta Grossa, uma vez que os resíduos são descartados em frente ao Matadouro Municipal, local este a céu aberto, sem condições adequadas, sem nenhum reaproveitamento.

Neste sentido, a partir de entrevistas realizadas com funcionários de ambos os órgãos, fica evidente a diferenciação das estruturas relacionadas à arborização urbana de Ponta Grossa, fato que se reflete na organização espacial da mesma.

\section{REFERÊNCIAS}

BARATTA JUNIOR, A.P.; Utilização do composto de resíduos da poda da arborização urbana em substratos para a produção de mudas. 2007, 62 f. Dissertação (Mestrado em Ciências). Universidade Federal Rural do Rio de Janeiro, Seropédica, 2007.

BIONDI, D; NETO, E.M.L. Pesquisa em arborização de ruas. Curitiba: O Autor, 2011. 150 p.

BONAMETTI, J.H. Arborização urbana. Terra e Cultura, n. 36, p. 51-55, 2003.

COPEL. Arborização de vias públicas. Disponível em: http://www.copel.com/hpcopel/guia_arb/. Acesso em: 10 set. 2012.

IBGE - Instituto Brasileiro de Geografia e Estatística. Dados do Censo 2010. Disponível em: www.ibge.gov.br. Acesso em: 29 out. 2011.

LEAL, L. Custo das árvores de rua - Estudo de caso: Cidade de Curitiba/Pr. 2007. 124 p. Dissertação. (Ciências Florestais). Setor de Ciências Agrárias. Universidade Federal do Paraná. Curitiba. 2007.

LIMA, A. M. L.P; CAVALHEIRO, F.; NUCCI, J.C.; SOUSA, M.A.L.B.; FIALHO, N. DEL PICCHIA, P.C.D. Problemas de utilização na conceituação de termos como espaços livres, áreas verdes e correlatos. In: CONGRESSO BRASILEIRO SOBRE ARBORIZAÇÃO URBANA, II Anais... São Luiz: Imprensa EMATER/MA, 1994. p. 539-553

LOBODA, C. R.; DE ANGELIS, B. L. D. Áreas Verdes Públicas Urbanas: Conceitos, Usos e Funções. Revista Ambiência - Revista do Centro de Ciências Agrárias e Ambientais. V. 1 no1 2005. p. 125 a 138.

LOURO, C.A.L; MENEZES, J. O Planejamento na gestão ambiental urbana dos municípios brasileiros. Caderno de Estudos Geoambientais - CADEGEO. V.3 no1 2012 p 62-75

LUZ J. R. Arborização urbana viária do bairro Órfãs em Ponta Grossa-PR. Trabalho de Conclusão de Curso (Graduação em Geografia) - Universidade Estadual de Ponta Grossa, Ponta Grossa, 2009. 
MALAVASI, U.C; MALAVASI, M.M: Avaliação Da Arborização Urbana Pelos Residentes - Estudo De Caso Em Mal. Cândido Rondon, Paraná. Revista ciência Florestal. V.11 no1. 2001. p. 189-193

MEISTER, I. Levantamento da arborização das vias públicas do bairro de Nova Rússia em Ponta Grossa - Paraná. Trabalho de Conclusão de Curso (Especialização em Gestão Ambiental) - Universidade Estadual de Ponta Grossa, Ponta Grossa, 2009.

MILANO, M.S. Métodos de amostragem para avaliação de ruas. In: Congresso Brasileiro sobre Arborização Urbana, 2, São Luiz, 1994. Anais... São Luiz: SBAU, 1994. p.163-168

MIRANDA, T. Arborização urbana viária no bairro da Ronda, Ponta Grossa - PR: composição e avaliação. 2008. Trabalho de Conclusão de Curso (Graduação em Geografia) - Universidade Estadual de Ponta Grossa, Ponta Grossa, 2008.

PARANÁ. Comitê de Trabalho Interinstitucional para Análise dos Planos Municipais de Arborização Urbana no Estado do Paraná. Manual para elaboração do Plano Municipal de Arborização Urbana. Mai. 2012. p. 1-18.

PIZZOL, K.M.S. A dinâmica urbana: uma leitura da cidade e da qualidade de vida no urbano. Caminhos de Geografia. V. 1, Fev.2006. p.1-7

PREFEITURA MUNICIPAL DE PONTA GROSSA. PLANO DIRETOR (Coletânea da Legislação), Ponta Grossa, 2006. Disponível em: www.pontagrossa.pr.gov.br. Acesso em: 10 abr. 2012.

QUADROS, G. P. Arborização Urbana na Área Central de Ponta Grossa: Implantação, Preservação e Monitoramento 2005. - Trabalho de Conclusão de Curso (Graduação em Geografia) - Universidade Estadual de Ponta Grossa, Ponta Grossa, 2005.

. (Des)construção do espaço verde em Ponta Grossa - Paraná - 2009, 136f. Dissertação (Mestrado em Gestão do Território) - Universidade Estadual de Ponta Grossa, Ponta Grossa, 2009.

REZENDE, D.A; FREY, K. Administração Estratégica e Governança Eletrônica na Gestão Urbana. Revista Eletrônica de Gestão de Negócios. Abril. P 51-59, 2005.

SANTOS, N. R. Z.; TEIXEIRA, I. F. Arborização de Vias Públicas: Ambiente x Vegetação. RS: Clube da árvore, 2001. $135 \mathrm{p}$.

SILVA, R. K. D. Arborização Urbana Viária no Bairro de Olarias, Ponta Grossa/PR. 2006. Trabalho de Conclusão de Curso (Graduação em Geografia) - Universidade Estadual de Ponta Grossa, Ponta Grossa, 2006.

VILELA, J. C. Levantamento Quantitativo e Qualitativo de indivíduos arbóreos presentes nas vias do Bairro Estrela em Ponta Grossa/Pr. 2007. Trabalho de Conclusão de Curso (Graduação em Geografia) Universidade Estadual de Ponta Grossa, Ponta Grossa, 2007. 


\section{ANEXO 1}

Roteiro das entrevistas realizadas com funcionários dos órgãos relacionados à arborização

\section{Local: PREFEITURA MUNICIPAL DE PONTA GROSSA - Secretaria de Agricultura,} Pecuária e Meio Ambiente.

Função:

1. Há uma estimativa do total de árvores plantadas na cidade?

2. Quais são as secretarias que se ocupam das atividades relacionadas à arborização das ruas? Secretarias - funções - número de funcionários.

3. Qual o valor da multa por corte indevido de árvores? O Sr (a) poderia exemplificar alguns casos por meio de processos arquivados ou em andamento?

4. Existe um programa de plantio de árvores, ou são plantadas aleatoriamente?

5. Há um monitoramento das árvores das vias?

6. Despesas com água, luz, telefone, materiais de escritório - há uma estimativa do valor, anualmente?

7. Salários dos envolvidos das secretarias da prefeitura

\section{Local: Departamento de Obras e Serviços Públicos}

Função:

1. Quantas pessoas realizam a tarefa de plantio, irrigação, poda e manutenção das árvores? O porte da árvore influencia? Quais são os equipamentos necessários?

2. Existe um cronograma para essas atividades?

3. Para onde vão os resíduos das podas, e de árvores mortas?

4. Os veículos são próprios?

5. Despesas com água, luz, telefone, materiais de escritório - há uma estimativa do valor, anualmente?

6. Qual é o salário dos envolvidos? 


\section{Local: Viveiro Municipal}

Função:

1. Como ocorre a aquisição de insumos e demais produtos necessários?

2. Qual é o tempo de permanência no viveiro? O porte e o tempo de crescimento influenciam?

3. Despesas com água, luz, telefone, materiais de escritório, equipamentos (quantos e quais?) - há uma estimativa do valor, anualmente?

4. Salários dos envolvidos

5. O terreno do Viveiro é público? Quantos metros? Há quanto tempo funciona?

\section{Local: COPEL}

Função:

1. Com quantas árvores da cidade a COPEL trabalha?

2. Quantos são os funcionários envolvidos na arborização urbana?

3. Há um cronograma anual?

4. Qual é o custo de poda? O porte influencia?

5. Quais são os equipamentos utilizados?

6. Para onde vão os resíduos, qual é o custo? 